\title{
Workshop: Digital Netizens at the Crossroads of Sharing and Privatising ${ }^{\dagger}$
}

\author{
Mark Carrigan ${ }^{1}$, Christopher Coenen ${ }^{2}$, José María Díaz Nafría ${ }^{3,4,5}$, Klaus Fuchs-Kittowski ${ }^{6}$, \\ Thomas Herdin 7, Wolfgang Hofkirchner ${ }^{8, *}$ and Rainer E. Zimmermann 5,9 \\ 1 The Sociological Review, Goldsmiths, London SE14 6NW, UK; mark@markcarrigan.net \\ 2 Karlsruhe Institute of Technology, 76131 Karlsruhe, Germany; christopher.coenen@kit.edu \\ 3 University of León, Spain, Campus de Vegazana s/n, 24071 León, Spain; jdian@unileon.es \\ 4 Universidad Estatal Península de Santa Elena, 240350 La Libertad, Ecuador \\ 5 Munich University of Applied Sciences, 80636 München, Germany \\ 6 Hochschule für Wirtschaft und Technik Berlin, 10318 Berlin, Germany; fuchs-kittowski@t-online.de \\ University of Salzburg, 5020 Salzburg, Austria; thomas.herdin@sbg.ac.at \\ Bertalanffy Center for the Study of Systems Science, 1040 Vienna, Austria \\ 9 Institut für Design Science München, 80797 Munich; pd00108@mail.lrz-muenchen.de \\ * Correspondence: wolfgang.hofkirchner@bcsss.org \\ + Presented at the IS4SI 2017 Summit DIGITALISATION FOR A SUSTAINABLE SOCIETY, Gothenburg, \\ Sweden, 12-16 June 2017.
}

Published: 7 August 2017

Organizers: IS4SI SIG Emergent Systems, Information and Society (supported by the Leibniz-Sozietät der Wissenschaften zu Berlin and the Bertalanffy Center for the Study of Systems Science) and the Institut für Design Science München

In 1997, a review was published of the development of the Net ("a new social institution, an electronic commons") pushed by the Netizens, as Michael Hauben baptised them. These were people online who "understand the value of collective work and the communal aspects of public communications", but who at that time were already challenged by "the increasing commercialization and privatization of the Net" (R. and M. Hauben: Netizens, On the History and Impact of Usenet and the Internet). The dynamics of capitalism itself has mixed up what seemed to be two kinds of poles with respect to the production of goods and services. Indeed, as Hardt and Negri observed, "producers increasingly require a high degree of freedom as well as open access to the common, especially in its social forms, such as communications networks, information banks, and cultural circuits" (Hardt and Negri: Commonwealth).

Two decades later, it's time to ask: Where do we stand today? Which hopes have come true? What setbacks do we need to report? And where are we heading? Are these dynamics of digital capitalism contributing to a new social order grounded on the commons?

We asked for one-page abstracts that are concerned with, but not restricted to, a range of topics:

- Dynamics of cultural, social, economic and political interaction in digital networks

- Digital commons and co-operation vs. digital privatisation and commodification

- New forms of participation and empowerment in the information society

- Sharing, networking and self-exploitation

- Prosumers, new DIY cultures and consumerism

- Hacking and capitalism

- Work between freedom and necessity

- Bubbles and rational vs. irrational discourse on social media

- Cross-cultural comparison: methodological challenges and research paradigms 
- The influences of values on information societies (regarding intercultural and transcultural dimensions)

- The representation of the Western information society in the Asian academic discourse.

Out of more than 20 submissions, 15 abstracts were, finally, presented at the workshop. The following contributions are selected for publication.

(C) 2017 by the author. Licensee MDPI, Basel, Switzerland. This article is an open access article distributed under the terms and conditions of the Creative Commons Attribution (CC BY) license (http://creativecommons.org/licenses/by/4.0/). 